\title{
Determining the interfaces parameters for geotechnical modelling
}

\author{
Armen Ter-Martirosyan, Vitalii Sidorov* and Anastasia Almakaeva \\ Moscow State University of Civil Engineering, Yaroslavskoe shosse, 26, Moscow, 129337, Russia
}

\begin{abstract}
The article discusses the interaction of concrete structures with the soil, made on the basis of laboratory tests and numerical simulation. The objectives of the study were to obtain the strength characteristics at the contact of two different materials, to compare the obtained value of the strength reduction factor with the standard values, and also to determine the extent to which the interface must be taken into account when conducting numerical geotechnical calculations. The study was carried out using a direct shear test device, where the strength reduction factor was obtained, which characterizes the conditions of interaction between different materials at their contact. According to the results of numerical simulation, one can see how the consideration of the given characteristics of the material of the contact element affects the internal forces arising in the underground structure and its displacements. The test results showed that the particle diameter has a different effect on shear strength at the same level of normal stress. On the basis of the results obtained, conclusions were drawn on what needs to be paid more attention to when conducting laboratory tests, how strongly the consideration of contact elements with the correct set of properties affects the internal forces of the underground structure. Also, the remaining problems and factors not considered in this study determined the prospects for further research on the topic under consideration.
\end{abstract}

\section{Introduction}

The interaction between different materials of construction and soils is an important problem in geotechnics. It is widely used in solving problems associated with the calculation of retaining walls, sheet piling, lowering wells, etc. The determination of the ultimate shear resistance is influenced by many factors, such as soil type, particle size, soil moisture, density, relative roughness, solid surface material, normal stress. However, according to numerous studies, soil moisture and relative roughness have the greatest effect, implying the ratio of the roughness of a solid surface along the shear length to the average diameter of the soil particles.

This topic has been studied in a number of other works, including foreign ones, for example, Liming $\mathrm{Hu}$ and Jialiu Pu (2004) [1] have carried out shear tests on a steel plate with its various roughness. In this work, two types of fracture were shown, depending on the relative roughness, and the thickness of the soil shear zone was visually determined.

\footnotetext{
* Corresponding author: vitsid@ mail.ru
} 
Other effects are described in many articles that are about steel-soil interaction [2-5]. A. Mohammadi, T. Ebadi and A. Eslami (2017) [6] investigated the effect of different roughness of a concrete surface on the shear resistance between sand and concrete in a shear device. In H. Haeri, V. Sarfarazi, and Z. Zhu (2019) [7] investigation was made a shear process between clay soil and concrete surface, and it was concluded that the roughness of the concrete and the applied normal stress affect the ultimate shear resistance. In addition, in a number of other works, the coefficient of strength reduction at different levels of normal stresses was determined and the values obtained varied from 0.4 to 0.9 . Table 9.1 SP 22.13330.2016 "Bases of buildings and structures" presents a table of the values of the strength reduction factor depending on the type of soil, its degree of moisture and consistency.

This topic has several approaches to the study that have emerged in the present. Among them are the development of models for the interaction of soil and structures [8-11], the conduct of test studies of the interaction of dissimilar materials [12-16], and the performance of numerical simulations to verify the found effects that occur in the interaction of structures with the soil [17-18]. In this paper, the authors used the last two directions as the main ones for obtaining the required interface parameters and using them in geotechnical numerical calculations.

Since in domestic geotechnical practice only a recommendation is given on the use of interface parameters presented in regulatory documents, but no explanation is given as to what ignores these parameters, the main task of the research is to compare calculations with direct determination of parameters and with complete or partial absence of interfaces on the contact surfaces [19-20].

\section{Methods}

For the tests fine and coarse dry sands were used and as a solid surface - a concrete plate with a diameter of $71.4 \mathrm{~mm}$ and a height of $16 \mathrm{~mm}$ from a cement-sand mixture of the brand M300. Grinding of the concrete surface with a large emery paper was carried out in a circular, uniform motion to obtain the same roughness in all directions. After the test, the concrete sample was rotated by $30^{\circ}$, since sand particles during shear may form grooves on the concrete surface, and also so that during the next test the particles did not move along the already formed trajectory (groove) but moved along the newly formed one. Otherwise, the obtained values of the tangential stresses will be underestimated since the limiting shear resistance will be less.

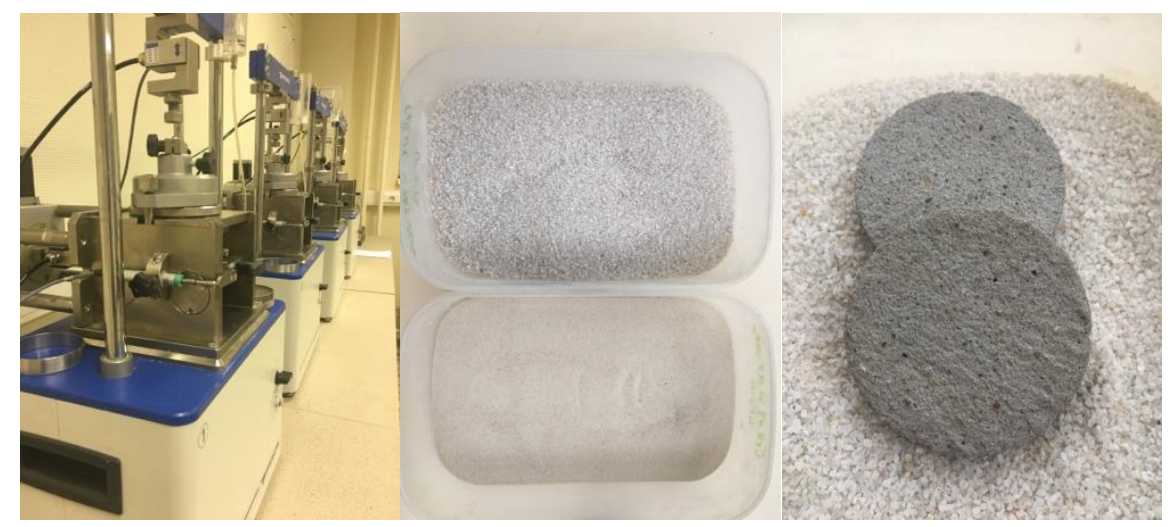

Fig. 1. The direct shear test machines, two types of sands and the concrete plates (from left to right) 
A total of 48 tests were conducted: 36 tests with fine sands and 12 tests with coarse sands. The tests were carried out on the direct shear test machines. The time of preliminary compaction of the soil was 10 minutes, the shear rate $-0.2 \mathrm{~mm} / \mathrm{min}$. For fine sands, the gap was set to a value of 0.2-0.4 mm, and for coarse sands - $1 \mathrm{~mm}$. The size of the gap was chosen in such a way as to eliminate particles falling out from there, thus more correct results are obtained without loss of material.

In numerical modelling, it is necessary to take into account the coefficient of strength reduction in the interface in order to correctly simulate moving contact between the structure and the soil. To determine its effect on the forces arising in the structures, as well as on their displacement and deformation, a test problem was calculated, which was calculated in PLAXIS 2D 2018. The retaining wall of the excavation is represented in the model by a plate element. The task was calculated in 3 stages:

1) without setting any interfaces;

2) with interface at Rinter $=1$;

3) with the interface at Rinter $=0.6$ (average values obtained from laboratory tests).

Characteristics of the interfaces were set not by the material of the adjacent soil cluster, but by the data set for the interface material, while the specific cohesion was $0(c=0)$, and the angle of internal friction was multiplied by the coefficient Rinter.

\section{Results}

The results of the 1 st and 2 nd series of tests carried out with fine and coarse sands are presented in Table 1. The reduction factor for the strength of Rinter is obtained by dividing the ultimate shear resistance between soil and concrete by the limit shear resistance between soil and soil (traditional direct shear test).

According to the results of the 1 st test series, the strength reduction factor Rinter varies from 0.34 to 0.8 . Most of the tests show the results of the Rinter values in the range from 0.52 to 0.71 , which, in general, corresponds to the intended range of values in accordance with current regulatory documents. However, 6 results are strongly knocked out of the mentioned range, which is not realistic from the point of view of the physics of the process and for this stage of the research were rejected.

Table 1. Testing results on fine and coarse sands

\begin{tabular}{|c|c|c|c|c|c|c|}
\hline & \multicolumn{3}{|c|}{ Fine sand } & \multicolumn{3}{c|}{ Coarse sand } \\
\hline Test No. & \multicolumn{2}{|c|}{$\tau_{\text {lim }}, \mathbf{k P a}$} & Rinter & \multicolumn{2}{c|}{$\tau_{\text {lim }}, \mathbf{k P a}$} & Rinter \\
\hline & soil by soil & $\begin{array}{c}\text { soil by } \\
\text { concrete }\end{array}$ & & $\begin{array}{c}\text { soil by } \\
\text { soil }\end{array}$ & $\begin{array}{c}\text { soil by } \\
\text { concrete }\end{array}$ & \\
\hline 1 & 28.8 & 16.7 & 0.58 & 27.9 & 28.8 & 1.03 \\
\hline 2 & 28.5 & 19 & 0.67 & 27.9 & 28.8 & 1.03 \\
\hline 3 & 28.5 & 17.4 & 0.61 & 27.9 & 28.8 & 1.03 \\
\hline 4 & 27.0 & 14.1 & 0.52 & 27.9 & 28.8 & 1.03 \\
\hline 5 & 27.5 & 19.5 & 0.71 & 27.9 & 28.8 & 1.03 \\
\hline
\end{tabular}




\begin{tabular}{|c|c|c|c|c|c|c|}
\hline 6 & 27.9 & 16 & 0.57 & 27.9 & 25.2 & 0.9 \\
\hline 7 & 27.9 & 16.1 & 0.58 & & & \\
\hline 8 & 27.9 & 16.1 & 0.58 & & & \\
\hline 9 & 27.9 & 18.7 & 0.67 & & & \\
\hline 10 & 27.9 & 17 & 0.61 & & & \\
\hline 11 & 27.9 & 16.7 & 0.6 & & & \\
\hline 12 & 27.9 & 14.4 & 0.52 & & & \\
\hline 13 & 27.9 & 9.5 & 0.34 & & & \\
\hline 14 & 27.9 & 10.2 & 0.37 & & & \\
\hline 15 & 27.9 & 10.3 & 0.37 & & & \\
\hline 16 & 27.9 & 10.5 & 0.38 & & & \\
\hline 17 & 27.9 & 9.5 & 0.34 & & & \\
\hline 18 & 27.9 & 22.3 & 0.8 & & & \\
\hline
\end{tabular}

To test the degree of influence of the parameters of the interface elements on the results of geotechnical modelling, a number of numerical calculations were carried out. As a geotechnical situation, a real system "retaining wall - soil", erected under the protection of a metal tube system, was selected. A stage construction of a deep excavation was simulated with and without taking into account the interface elements between the concrete and soil.

Figure 2 show plots of bending moments of the embedded in soil structure, obtained at the time of full excavation. From them it can be seen that with the advent of the interface on the "soil-wall" contact, the bending moment changes by $15 \%$, while the strength characteristics at the contact decrease, the bending moment increases by another $10 \%$. That is, the difference between a task without using a contact element and a task with regard to contact elements and taking into account reduced strength characteristics reaches $25 \%$. In addition, it should be noted that the change in the magnitude of the moment along the wall is not uniform. Thus, we can conclude that it is necessary to take into account and correctly define the interface elements when modelling, because in reality the stiffness on the "soilwall" contact will be less, therefore displacement and separation corresponding to contact parameters may occur. 

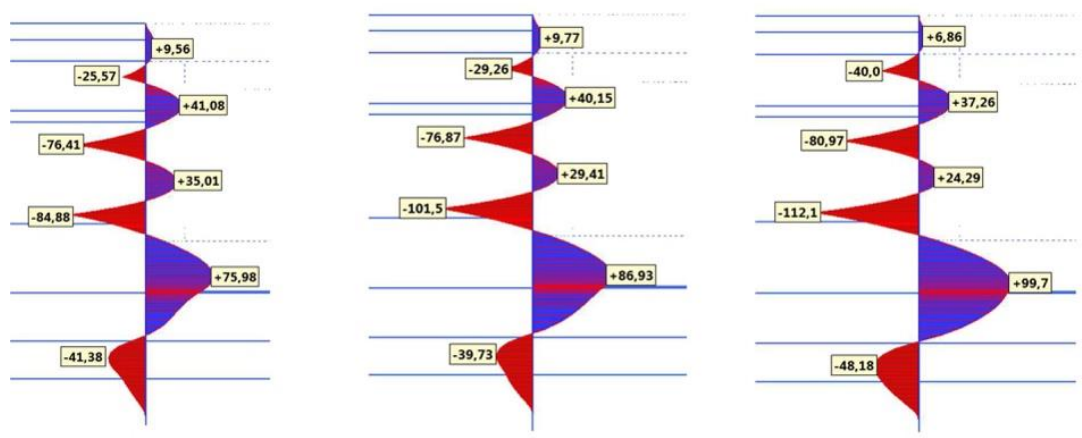

Fig. 2. The curves of bending moment in the retaining wall.

(left) - without any interfaces between materials, (central) - with a rigid interface (Rinter=1), (right) - with an interface value from the results of the direct shear tests

\section{Discussion}

Obtaining incorrect values (knocked out of the results set) can be explained by the fact that in fine sand the particle size is much smaller than the size of the gap. When shifting into the gap, several rows of particles fit in, therefore the shift occurs both in concrete and in the ground, which leads to an overestimated value of the ultimate shear resistance [12]. Hence the need to study the thickness of the contact zone of the soil shear, which is involved in the work and determines the amount of resistance. However, as the size of the gap decreases, particles can become jammed. In this case, the gap will prevent the effect of dilatancy, rotation and rolling of particles, therefore the shift will occur according to a specific scenario, which will differ from the shift having a certain thickness of several layers of particles. There is also a possibility that the device will not work correctly due to jamming, so the results can be out of the general range of values obtained.

After rejecting the results, the average value of the obtained strength reduction factor is Rinter $=0.6$, which is similar to that presented in Table 9.1. SP 22.13330.2016 Grounds of buildings and structures is equal to 0.67 .

According to the results of the 2 nd series, it can be seen that the resistance to shear between the coarse sand and the concrete sample is slightly higher than the resistance to shear on the ground. The coefficient Rinter $=1.03$, i.e., is practically equal to 1 . This phenomenon can be explained by the fact that because of the size of the gap, comparable to the size of sand particles, the contact provides direct friction between the particle (separate rock) and the concrete stone. Since the hardness of sand particles is equal to or greater than the hardness of concrete on the contact surface, characteristic grooves may form, which makes it necessary to turn the concrete die from test to test to ensure comparable experimental conditions.

\section{Conclusions}

1. Tests on a direct shear machine showed a wide variation in test values between fine sand and a concrete sample, since the shear process is sensitive to the size of the gap. Its value should be chosen depending on the grain size: if the gap is smaller than the particle size, then particles will jam, preventing the formation of some contact layer that is included in the work, however, if the gap exceeds the particle size, then several rows of particles will fit the gap as a result, the shift will occur both on the concrete surface and in the soil. 
2. Tests carried out with coarse sand showed good repeatability of the results of the obtained values of the ultimate shear resistance and, accordingly, of the strength reduction factors.

3. Numerical simulation showed that the bending moment in the embedded reinforced concrete wall of the deep excavation increases by $25 \%$ when using contact elements with a set of specified properties defined in the laboratory, which significantly affects the further design of this structure in terms of reinforcement and material selection.

4. In addition to the strength reduction factor, the thickness of the soil shear zone (interface thickness) must also be taken into account. As the number of rows involved in the shear process increases with decreasing particle size. Accordingly, this factor will affect the ultimate shear resistance. However, at the moment, this factor has little knowledge of international scientific practice, which makes it interesting for further research on the processes occurring during the interaction of building structures with a soil mass.

This work was financially supported by the Ministry of Education and Science (state task \# 7.3225.2017/4.6). All tests were carried out using research equipment of The Head Regional Shared Research Facilities of the Moscow State University of Civil Engineering.

\section{References}

1. L.M. Hu, J.L. Pu, JGGE, 130, 851-860 (2004)

2. M. Saberi, C.-D. Annan, J.-M. Konrad, ACME, 18, 1562-1579 (2018)

3. S. Jiang, C. Du, L. Sun, Geomech. and Eng., 16, 3, 309-320 (2018)

4. A. Di Donna, A. Ferrari, L. Laloui, Can. Geotech. J., 53, 659-672 (2017)

5. A.O. Ilori, N.E. Udoh, J.I. Umenge, IJGE, 8, 17 (2017)

6. A. Mohammadi, T. Ebadi, A. Eslami, Geomech. Eng., 12, 211-221 (2017)

7. H. Haeri, V. Sarfarazi, Z.M. Zhu, Smart Struct. Syst., 23, 81-90 (2019)

8. X.B. Chen, J.S. Zhang, Y.J. Xiao, J. Li, Can. Geotech. J., 52, 1122-1135 (2015)

9. Z.H. Xu, G.D. Zhang, W. Liao, A.M. Liao, and al., JAER, 78, 547-551 (2016)

10. Hisham T., Eid, Ruslan S., Amarasinghe, Khaled H., Rabie and D.Wijewickreme, Can. Geotech. J., 52, 198-210 (2015)

11. P. Du, X.L. Liu, B. Yang, JAER, 15, 426-429 (2015)

12. M. Huang, Y. Chen, X. Gu, Computers and Geotechnics, 107, 14-24 (2019)

13. B. Pardoen, J.-M. Konrad, J. of Geotech. and Geoenv. Eng., 145, 3, 04018111 (2019)

14. M.D.L. Millen, S. Pampanin, M. Cubrinovski, Proceed. of the Inst. of Civ. Engin. Geotech. Eng., 172, 1, 16-29 (2019)

15. M. Saberi, C.-D. Annan, J.-M. Konrad, Soil Dyn. and Earthquake Eng., 116, 714-731 (2019)

16. D. - K. Feng, J.-M. Zhang, W. -J. Hou, J. of Geotech. and Geoenv. Eng., 144, 12, 04018095 (2019)

17. M. Khemissa, N. Tallah, B. Bencheikh, Innov. Infrastr. Solutions, 3, 1, 25 (2018)

18. D.-K. Feng, J.-M. Zhang, L.-J. Deng, Can. Geotech. J., 55, 11, 1657-1667 (2018)

19. P. Yang, S.-B. Xue, L. Song, M.-S. Duan, Int. J. of Geo-Eng., 9, 1, 12 (2018) 